\title{
Estudos sobre Jorge Andrade
}

\author{
Elisabeth Azevedo
}

orge Andrade é, acredita-se, o autor que apresenta uma das obras dramáticas mais orgânicas do teatro brasileiro. Elaborada ao longo de mais de trinta anos, foi permanentemente autoquestionada e permaneceu comprometida com a (re)construção da nacionalidade, sem que ele nunca abrisse mão da seriedade e da autenticidade artísticas. Como disse Sábato Magaldi,"poucos autores, entre nós, empenharam-se como Jorge Andrade na construção de um verdadeiro monumento dramático." (1977, p. 302) O mesmo crítico sustenta que "nenhuma outra obra, em nossa dramaturgia, construiu tão laboriosamente a sua unidade." (1998, p. 52-3) O que interessa aqui é pensar essa condição de obra unitária a partir da perspectiva de que Jorge Andrade foi também repórter, escritor de telenovelas e autor de um romance autobiográfico. Para ilustrar a forma coerente e reiterativa com que Jorge procurava retratar a realidade, veja-se o conjunto de crônicas escritas para a Folha de São Paulo, que completam e reforçam ainda mais aquele conceito de organicidade. Nessas crônicas, encontram-se muitas vezes os temas tratados nas peças. Acham-se 'trechos' que parecem ter sido suprimidos (ou es- tendidos) das peças publicadas. No eterno entrelaçamento das várias facetas da obra andradina, citem-se dois exemplos interessantes. O primeiro é uma crônica publicada na Folha de São Paulo em 26 de janeiro de 1979. Com o título "A maior criação", é claramente uma cena que poderia pertencer a Milagre na cela, se colocada no I ato, entre as cenas 23 e $24^{1}$. Na crônica, lê-se:

"Ela é uma verdadeira educadora e sabe que milhares de homens, através dos tempos, ensinaram com a própria morte. Sente que é por causa disto que seus torturadores não a dobram: ela sabe que a morte pode ser a mais bela das liçōes!

Foi no meio deste pensamento que ela sentiu a dor aguda: o homem que a leva prisioneira dera-lhe um murro nas costas. Ela cambaleia e sente novamente a presença do mundo odiento onde está. Com o murro vem a voz cheia de espinhos envenenados:

- Vamos mais depressa. Que está pensando? Que passeia na praça?

- Praça?

- Praça pública.

- Nunca andei numa. Nem existe nessa cidade. - Nunca andou porque vivia tramando.

* Elisabeth Azevedo é pesquisadora e doutora pelo CAC-ECA-USP.

1 Na verdade, não há divisão em cenas nessa peça. A indicação aqui apresentada resulta de uma marcação feita apenas para efeito de análise da obra. 
- Tramando o quê?

- A subversão.

- Nunca fiz subversão.

- E aquilo que ensinou pros alunos?

- Ensinei a verdade. Só a verdade.

- Verdade mentirosa. E vamos andando. Ago-

ra você vai ver se confessa ou não confessa.

Vai ter um tratamento especial.

- Que tratamento?

- Você verá.

Tratamento especial! Nenhum temor passa em sua mente. O que de mais horrível poderá acontecer, além de assistir à degradação do homem? Não só dos torturados, mas também dos torturadores, pois torturar não é se degradar? O seu sofrimento é duplo: pelos martirizados e pelos que martirizam. Seu rosto não se contorce apenas pela dor física, mas também por ver o homem se transformando em besta. Torturados e torturadores! Onde não existem neste mundo que parece abandonado por Deus? A tortura não acompanha o homem na sua caminhada para o amanhã? [...] não faz parte da aventura humana? Torturados e torturadores não são expressões do bem e do mal que alimentam esta aventura? Qual religião, ideologia ou cultura libertará o homem de seus demônios? Por que está presa de uma dos piores - a intolerância! - se só tem amor pelo próximo e paixão de ensinar dentro de si mesma? Em nome de seus alunos - brasileiros do amanhã -, agüentará tudo para não admitir a mentira que escraviza. Subitamente, o homem pára e se volta para ela com um sorriso que fere como navalha.

- É aqui.

Ela olha a porta estreita com uma janelinha. Ao lado da porta, uma alavanca. Sem saber por quê, sente um pressentimento de agonia. O sorriso se acentua no rosto do homem e seus olhos brilham de maldade. Instintivamente, ela aponta a alavanca.

- Que é isto?
- Alavanca de descarga.

- Descarga?

- Da privada

O sorriso torna-se fixo, assassino, enquanto ele introduz a chave na fechadura. Sons ferrugentos lembram arrastar de correntes, de ferro contra ferro. Ele pára de girar a chave e se volta para ela, antegozando o prazer do torturador:

- Só quem está fora pode dar descarga na privada.

Rápido, ele a empurra para dentro e tranca a porta. ${ }^{2}$ Cubículo de dois metros por dois metros e uma privada entupida. O odor enfia as garras em sua garganta, expulsando o ar de seus pulmóes. Ela enfia as unhas nas paredes, voltando-se sufocada para a porta. A janelinha se abre, desenhando-se na escuridão com um olho maldito e deixando passar a risada que é tão horrível quanto o mau cheiro. Ela reúne um resto de energia para gritar: - Por favor, abra a porta! [...]

E a grande educadora paulista cai de joelhos, implorando a Deus pelo homem. Por todos os homens que agonizam em prisões fascistas, comunistas e democratas relativas."

Conforme se pode ver, Jorge adaptou o material com o qual estava trabalhando para fazer pequenas experiências, talvez como balóes de ensaios ou como uma espécie de 'propaganda' velada, já que, à época da ditadura militar, sua peça estava proibida pela Censura.

O exemplo seguinte, uma crônica tirada da edição da Folha de São Paulo de 16 de março de 1979 e intitulada "A mesa", pode ser visto como texto que dava continuidade a Senhora na Boca do Lixo. A crônica se refere a uma descendente falida de antigos fazendeiros que conseguiu emprego público na Secretaria da Justiça de São Paulo, graças a um amigo da família. No meio da sala do pequeno apartamento onde mora, há uma enorme mesa de jantar, herança

2 A partir desse trecho, a crônica se sobrepõe à peça. 
familiar, atravancando tudo. Entretanto, ela não consegue livrar-se do móvel - ninguém o quer. A cada vez que olha para ele, relembra a infância: Que tempo gentil! Por que foi desaparecer? Lê-se:

"Querendo se defender, a mesa parece crescer ainda mais, tentando esmagar Noêmia contra a parede. Noêmia recua, fascinada, e percebe que não é esmagar que a mesa pretende, mas acariciá-la e envolvê-la com seus pés, braços maternais [...].

- Livre-se de mim. Eu sou o passado que atormenta, as esperanças que não se realizam [...]. Noêmia pega a machadinha e fecha a porta [...]. Lentamente, aproxima-se da mesa como numa despedida. [...] durante um mês, diariamente, Noêmia foi picando a mesa [...]. $O$ último pedacinho foi com ela para dentro do mausoléu da família no Cemitério da Consolação, fechado na mão que ninguém conseguiu abrir para colocar o terço."

Essa mulher que perdeu tudo - a quem só restou a enorme, incômoda, inútil, linda e amada mesa de jantar - é a mesma Noêmia de Senhora da Boca do Lixo, tentando lidar com o passado e subjugada ainda por ele. A diferenciála da personagem da peça, está o fato de que, em parte, ela finalmente compreende e reage. $\mathrm{E}$ reage com violência cada vez maior, proporcional à sua decepção com a vida. Destrói a mesa e por extensão o passado - a golpes de machado, guardando apenas a memória indelével do que fora. Aliás, esse móvel que parece agigantarse com o correr da crônica tem algo de semelhante à multiplicação de objetos em algumas peças de Ionesco. Em Amédée, ou comment s'en débarrasser, por exemplo, o dramaturgo romeno faz cogumelos brotarem pelo apartamento fechado e um cadáver crescer ininterruptamente até transformar-se no balão que, de certa forma, liberta o protagonista. A reação a que se vê forçada a personagem da peça brasileira também a liberta.

A obra teatral e a atividade jornalística de Jorge Andrade se interpenetram, seja pelo reaproveitamento de temas das peças, seja pela dramatização de reportagens, como no caso de O mundo composto, peça de um ato que foi escrita com base numa matéria para a revista $R e a-$ lidade (Andrade, 1972).

Mais exemplar ainda é a forma com que Jorge usa o tema da Conjuração dos Alfaiates, ocorrida na Bahia em 1798. De início, tratou-o numa reportagem também de Realidade, em novembro de 1971, e depois o retrabalhou em seu livro Labirinto. Os trechos desse romance autobiográfico em que apresenta a cena da execução dos conspiradores são verdadeiras cenas teatrais, cheias de tensão e suspense.

No mesmo romance, uma personagem já conhecida de seu teatro, o bandeirante Fernão Dias, surge novamente da imaginação e da memória do autor, em meio aos livros da biblioteca do historiador Sergio Buarque de Holanda.

Esse tipo de procedimento possibilita ao pesquisador buscar, em diferentes trabalhos do autor, relaçôes reveladoras. O uso da memória pessoal ou de uma 'memória coletiva' é fonte para diferentes abordagens, cujo caráter pode ser ou fundamentalmente estético, ou particularmente sociopolítico. 


\section{Referências bibliográficas}

FARIA, J.R. O teatro na estante. São Paulo: Ateliê, 1998.

FERNANDES, T.F.T.D. Jorge Andrade, repórter asmodeu: leitura do discurso jornalístico do autor na revista 'Realidade'. (Tese de Doutorado) - Escola de Comunicações e Artes, Universidade de São Paulo, São Paulo, 1989.

FRANCIS, Paulo. Diário Carioca. Rio de Janeiro, 17 abr. 1960.

GEORGOPOULOS, C.L. Lua quebrada: 'A moratória' no ciclo paulista de Jorge Andrade. (Dissertação de Mestrado) - Universidade Fluminense, Niterói, 1983.

GIMENEZ, A. Quem é o vencedor do prêmio Fábio Prado. Folha da Noite. São Paulo, 16 jul. 1954.

GUIDARINI, M. A diferença nos textos dramáticos de Jorge Andrade. (Dissertação de Mestrado) Faculdade de Filosofia, Letras e Ciências Humanas, Universidade de São Paulo, São Paulo, 1979.

GUINSBURG, J. Um teatro em rastro atrás: Jorge Andrade. Revista USP, São Paulo, v. 29, p. 1135, mar./maio 1996.

MAGALDI, S. Panorama do teatro brasileiro. São Paulo: Global, 1977. Moderna dramaturgia brasileira. São Paulo: Perspectiva, 1998.

NAZÁRIO, A.J.C. Tempo e memória no teatro de Jorge Andrade: uma leitura de 'Rasto atrás'. (Dissertação de Mestrado), Unicamp, Campinas, 1997.

PAVIS, P. Dicionário de teatro. São Paulo: Perspectiva, 1999.

ROSENFELD, A. Visão do Ciclo. In: ANDRADE, J. Marta, a árvore e o relógio. São Paulo: Perspectiva, 1986.

SANT'ANNA, C. Metalinguagem e teatro: a obra de Jorge Andrade. Cuiabá: Editora da UFMT, 1997.

SOUZA NETO, J. Jorge Andrade, um autor em busca de si mesmo. (Dissertação de Mestrado) Escola de Comunicações e Artes, Universidade de São Paulo, São Paulo, 1988.

UBERSFELD, A. Lire le théâtre. Paris: Belin, 1996. 3 v. 